\title{
Temporomandibular Joint Disorders and Preventive Methods in Boxing Athletes
}

\section{Elif Ozcan ${ }^{1}$ and Guhan Dergin ${ }^{2 *}$}

${ }^{1}$ Marmara University Faculty of Dentistry Department of Oral and Maxillofacial Surgery, Turkey

${ }^{2}$ Associate Professor, Marmara University Faculty of Dentistry Department of Oral and Maxillofacial Surgery, Turkey

\begin{abstract}
Oral and maxillofacial injuries are common in sporting activities, especially in contact combat sports. It has been stated by a number of researchers that obligatory dental and orofacial protection for all athletes have major effects in preventing injuries and associated life-long discomfort, as well as reducing the treatment costs. Boxing exposes athletes to severe head impacts and risk of brain injury, as well as disorders resulting from chronic recurrent traumas. The purpose of this report is to state the causes of temporomandibular joint disorders in boxing athletes and emphasize the importance of preventive measures and routine screening by a TMJ specialist maxillofacial surgeon.
\end{abstract}

Keywords: Temporomandibular joint disorder; Trauma; Boxing

\section{Introduction}

As a contact combat sport, boxing is an universally exercised discipline since earliest periods of history. Boxing exposes athletes to repetitive, occasionally severe head impacts. As a result, boxing athletes are among high-risk group for encountering maxillofacial and brain injuries [1].

Maxillofacial injuries and temporomandibular disorders are very common and comprises the results of various types of sporting activities such as soccer, skiing, basketball, cycling, hockey, snowboarding, boxing and other contact combat sports [2-4]. Contact sports are reported to be cause of about $19 \%$ of maxillofacial and $33 \%$ of dental injuries $[5,6]$. Retrospective analyses by Tanaka et al., and Mourouzis and Koumoura reported the incidence of boxing-related maxillofacial fractures as $2 \%$ and $1.6 \%$, respectively $[3,4]$.

Boxing-related injuries are considered more serious among other sports due to repetitive and direct traumas to head and face region, which are prohibited in other disciplines [7]. Kumamoto and Maeda reported that $33-72 \%$ of boxing athletes have encountered dental injuries in their career [8]. According to study examining the epidemiology of boxing injuries in the U.S. within a 19-year study period by Potter et al., the most common diagnosis was fracture (27.5\%). Most frequently injuried body region was the hand (33.0\%), followed by head and neck (22.5\%). Lacerations in this region involved face, mouth and eyes (87\%) [6]. As reported by Jerolimov, all orofacial injuries comprised soft tissue injuries (50\%), dental injuries (40\%), jaw fractures and temporomandibular joint injuries (10\%). Among these, injuries of TMJ and related structures consist of about $2-6 \%$ of cases, but there is lack of reliable data on this subject [9-12].

\section{Anatomy and Biomechanics of the Temporomandibular Joint}

The Temporomandibular Joint (TMJ) is a true synovial joint and composed of the temporal bone and the mandible, and a specialized dense fibrous structure, the distinct fibrocartilaginous articular disk, articular ligaments, and surrounding muscles. Anatomically the TMJ is a diarthrodial joint, which is formed by mandibular condyle and the glenoid fossa of the temporal bone. Movement of TMJ is adjusted by muscles of mastication, and limited by ligaments. Certain movements of mandible and opening against resistance requires the activation of suprahyoid and infrahyoid muscle groups, digastic and mylohyoid muscles $[13,14]$.
Functionally the TMJ is a compound ginglymoarthrodial joint. The lower compartment provides hinge motion and is termed as ginglymoid. The superior compartment conducts translatory movements and hence termed as arthroidal. Pure hinge motion of $2.5 \mathrm{~cm}$ measured at the interincisal opening is possible, further movements of the mandible involves translatory and involves a gliding motion between disk and the temporal fossa. Complex free movements of the mandible are made possible by the relation of four articulating compartments bilaterally [15].

\section{Temporomandibular Joint Trauma in Boxing Discipline}

Most of orofacial and temporomandibular injuries in boxing, are predictable and preventable. There are three main types of appliances exist as extraoral, intraoral (mouthguards) and combined ones. Intraoral appliances (mouthguards) can be stock, mouth-formed orcustom-made [16]. A continuing education should be followed on the importance of prevention methods for boxing injuries for sports physicians, coaches and athletes, thus making the role of the maxillofacial surgeon in this sport persistent [17].

Types of boxing injuries depends on impact areas on the maxillofacial region and mechanism of transmitted force. Magnitude and vector of the force, as well as absorbing mechanisms and transmitting patterns should be taken into account.

Traumatic effect of the force can be absorbed by surrounding musculatory, articular and extraarticular ligaments, articular disc and the teeth [9].

There are two essential mechanisms of boxing injuries and related TMJ disorders as microtraumas and macrotraumas in direct and indirect routes (Figure 1). Repeated trauma to the mandible can lead to inflammatory responses in the masticatory muscles, laxity of the ligaments, and TMJ internal derangements [14]. Microtraumasgenerated

*Corresponding author: Guhan Dergi, Marmara University Faculty of Dentistry Department of Oral and Maxillofacial Surgery, Turkey, Tel: 00902122535050; E-mail: guhandergin@yahoo.com

Received December 30, 2013; Accepted February 07, 2014; Published February 10,2014

Citation: Ozcan E, Dergin G (2013) Temporomandibular Joint Disorders and Preventive Methods in Boxing Athletes. J Sports Med Doping Stud 4: 134 doi:10.4172/2161-0673.1000134

Copyright: $\odot 2014$ Ozcan E, et al. This is an open-access article distributed under the terms of the Creative Commons Attribution License, which permits unrestricted use, distribution, and reproduction in any medium, provided the original author and source are credited. 


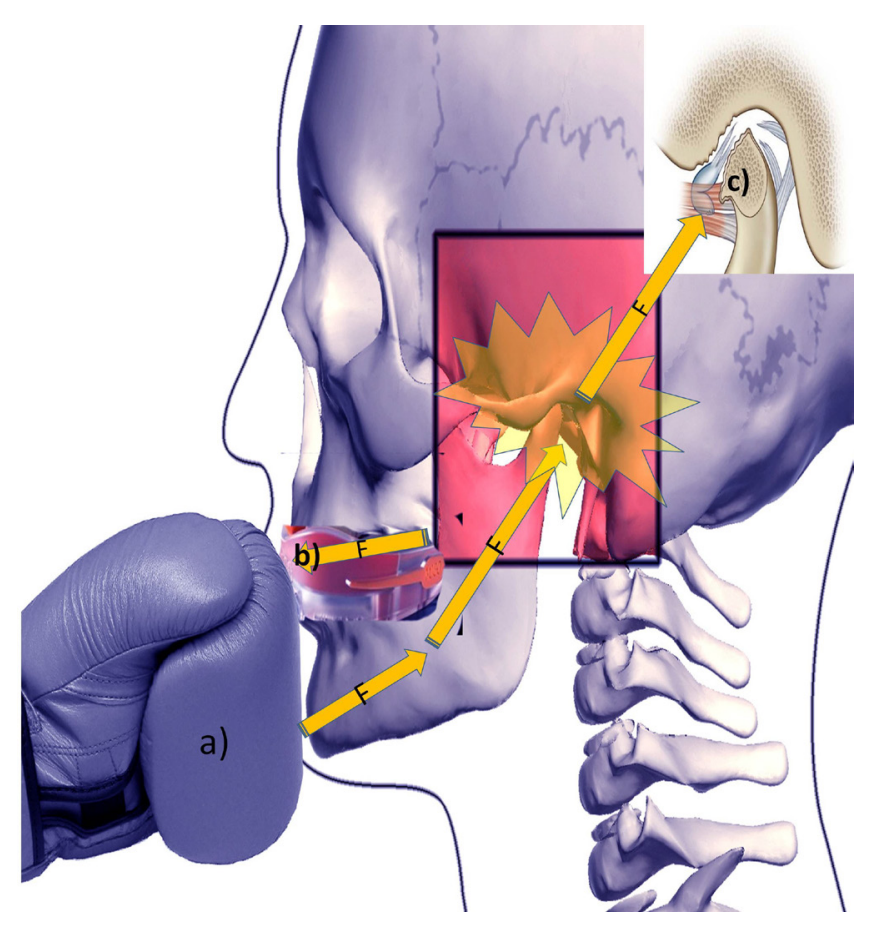

Figure 1: a) Direct or indirect blow trauma to the mandible which is conducted to the TMJ.

b) Mouthguard which fixates maxilla and mandible, so the condyle at a certain position, which decreased the transmitted forces to the condyle and articular structures.

c) Degenerated disk and articular surface of the temporomandibular joint with chronic macro and micro trauma.

by internal factors, such as chronic overloads and parafunctional habits such as bruxism and clenching. Constant clenching and lateral pterygoid muscle spasm during practice leads to disc deplacements in long term. Chronic microtraumas to the temporomandibular joint can result in synovitis, capsulitis, tendinitis, reducing and non- reducing disc deplacements, osteoarthritis, subluxation and condylar dislocation as well as periodontal disorders and luxation of the teeth [18-23].

Consistent microtrauma causes releasing of certain inflammatory mediators, such as NO, arachidonic acid and prostaglandin E2. These cytokines starts a cascade that leads decomposing of cross collagen content of the articular surfaces, which leads to degeneration of articular disc, retrodiscal tissues and eventually reducing and non-reducing disc deplacement [24]. Clinical symptoms of internal derangements include limited mandubular range of motion, deviation of the mandible to the affected side, joint sounds and pain, generally associated with painful sensation of muscular tissues [15].

Repetitive loading of articulation system may result in osteoarthrosis. Bruxism and clenching habits may mimic excessive load forces. Internal derangement of the temporomandibular joint leads to alteration of forces transmitted to condyle-glenoid fossa complex, thus weakening of the functional areas of join elements. These changes often results cartilage tissue proteoglicans to undergo destruction with decreasing lubricative and protective properties of the cartilage. Eventually, osteoarthrosis may lead to perforation of articular disc and/or remodeling of bony structures of the joint such as flattening of the condyle. Macrotraumas are external factors such as acute, high magnitude blows. These traumas likely will result in maxillo-mandibular and condylar fractures, condylar dislocations, dental traumas, fibrous or bony ankylosis, cranial base fractures and concussions. Bechor and Zadik reported a case of maxillary incisor being laterally luxated due to long term boxing practice without protection [18].

Traumatic arthritis represents the acute intraarticular response to temporomandibular joint trauma. The resulting inflammation effusion and occasional hemarthrosis causes limited range of mandibular movement, pain on the affected side. Direct blows to the mandible may result in anterior dislocation, capitular fractures, contusions of the condylar head and condylar neck fractures. Direct trauma to the sympyhseal area is likely to cause bilateral condylar fractures upon transmission of force, whereas blows to the parasympyseal area will likely cause fracture of contralateral condyle due to indirect conducting of trauma and rotational forces [25].

Besides taking medical history and clinical examination of the patient, diagnostic measures include plain panoramic radiographs, CT scans and MRIs [26]. It should be emphasized that, microtraumas are easily overlooked in diagnostic procedure, since their chronic and occasionally non subjectively-symphtomatic nature. Microtroumas has a cumulative effect on TMJ and it is the serious causative factor of TMJD. Besides athletes may not refer to microtraumas in their medical history, which can result in wrong diagnosis.

Depending on the type of disorder and/or injury, treatment modalities include, anti-inflammatory medications, analgesic drugs, myorelaxants, anestethics, soft diet regimen, passive opening excersises, heat applications, cold applications, arthrocentesis and surgical procedures under general anesthesia. Masticatory muscle disorder and disc derangement may lead to each other and frequently appear simultaneously, therefore it is essential to determine the primary disorder so that effective treatment may be executed. As a general rule, non-invasive and reversible forms of treatment should be initially performed for management and unnecessary surgical approaches should be avoided. According to the results, the need for more aggressive or irreversible forms of treatment may be determined. Since misdiagnosis is the most common reason for failure of the treatment, meticulous examination of underlying mechanism is mandatory for executing especially surgical treatment modalities [15].

Since such injuries, symptoms and their treatment process result in interruption of athlete's professional activities, risk of acute or chronic injuries should be limited or completely eliminated [21-23,27].

\section{Prevention of Maxillofacial and Temporomandibular Injuries}

Most of athletic injuries are predictable, therefore preventable. Protection and education of athletes are essential for reducing boxing related injuries and disorders. World Dental Federation (FDI) classified sporting activities into two risk groups in 1990, according to the risk level of orofacial injuries in which the protection is recommended [28]. Prevention of maxillofacial injuries in sports can be achieved by appliances such as helmets, face shields and mouthguards.

Many reports have demonstrated that using mouthguards can reduce the incidence of maxillofacial injuries significantly [29,30]. By absorbing, limiting, and distributing the power of impact that tends to be transferred along osseous structures of the skull to the central nervous system, mouthguards reduce the risk of cerebral concussion and subarachnoid hemorrhage [16]. Use of mouthguards are vital in preventing TMJ injury in any high risk sports and even became obligatory in certain disciplines such as skiing, hockey and boxing [31].

Mouthguards can be classified as three groups: 
- Extraoral mouthguards are attached to head or helmet and in the form of a wire cage.

- Intraoral mouthguards rest within dental arches, usually fits to maxillary teeth and shaped accordingly.

- Combined mouthguards have an extraoral part for soft tissues and intraoral part for protection of the teeth.

Intraoral mouthguards are superior appliances in various aspects, and have significant roles in mitigating trauma to the maxillofacial region [19,31].

- Reducing the risk of fractures and luxations in anterior dentition by direct blows and posterior dentition from sudden impacts

- Distributing the force and creating a recoil space allows the interface between condyle and glenoid fossa, hence preventing condylar dislocations towards the cranial base [32]

- Protection of soft tissues from being lacerated by edges of the teeth

- Reducing the possibility of maxillary and mandibular fractures by absorbing the impact force

- Increasing the athlete's ability to focus on performance by increased comfort

- By activation and contraction of head and neck muscles, providing increased resistance to rotational forces upon impact, and reducing injuries to cervical spine and possibility of concussions [33-36].

There have been three types of intraoral mouthguards have been used:

- Stock mouthguards are available commercially in varying sizes, composed of rubber or polyvinyl chloride. These type of mouthguards are not recommended by TMJ professionals although being most widely used.

- Mouth-formed mouthguards are preferred for their price and quick fabrication, but their retention decreases over time. These type of appliances can be manufactured by heating and shaping according to arch shape, or they can be prepared on cast models.

As presented by Shimoyama et al., boil and bite type of mouthguards considered to be limitedly effective against injuries due to unfitness. Lack of occlusion in mouthguards especially in intercanine area would instead increase the probability of injury, and cause mandibular and condylar fractures [37-39].

Custom-made mouthguards are fitted to dental arch, show higher retention and offer more effective absorption and distribution of forces. These appliances can also ensure the proper positioning of condyle in the fossa. Custom made mouthguards can be manufactured as monomaxillary and bimaxillary. Monomaxillary appliances mostly fit onto maxilla, except in cases of mandibular prognathism.

Bimaxillary appliances should have air openings for maintaining adequate breathing and stabilizes the mandible in order to reduce the risk of fractures as well as injuries to TMJ $[2,19]$.

Thickness of the material usually adjusted to 3-4 $\mathrm{mm}$ in general, which provides a adequate absorption of forces. Although being more difficult to use, vertical thicknesses up to $6 \mathrm{~mm}$ are used for high risk occasions.

Inappropriately manufactured mouthguards lead clenching habits



Figure 2: a) Stock-type mouthguard

b) Mouth-formed mouthguard

c) Custom-made mouthguard

by its own, and have insufficient protective properties by means of force tranmission to cranium and mandibular condyle. Therefore, these appliances should be produced under the supervision of TMJ specialists [34]. It has been reported that custom made mouthguards with adequate occlusal and labial thickness provides significant protection against maxillomandibular injuries by their resilient nature [16]. However, there is insufficient evidence confirming that usage of appliances prevent brain concussions $[8,33,40]$.

Several authors have tested the mechanical properties of mouthguards based on standards established by American Society of the Testing Materials (ASTM) [41,42]. Also, response of human mandible to the impact loading of the chin and relationship between joint dynamics and mouthguards have been studied on cadaver, fabricated hybrid dummy models and finite element models. Though there is no established standard test method exist for biomechanical evaluation of mouthguards [29,32,43,44] (Figure 2).

\section{Conclusion}

To prevent TMJ complications of boxing sport and early diagnosis of clinical signs of TMJ micro-macro trauma, boxers should be routinely examined by TMJ specialist maxillofacial surgeons and neurocognitive tests must be performed on a regular basis. Athletes should not wear mouthguards which is not approved and adjusted by TMJ specialist. Custom made mouthguards should be preferred for a better protection of temporomandibular joint structures and dental arch. In some cases, TMJ MRIs, clinical signs and TMJ sounds should be evaluated to identify the severity of the problem. After these, pharmacological, physical or surgical therapy should be executed. The profession should make efforts to promote the use of mouthguards by informing athletes of the possibilities of active prevention against injuries to dental/oral regions in order to reduce their incidence.

\section{References}

1. Gartland S, Malik MH, Lovell ME (2001) Injury and injury rates in Muay Thai kick boxing. Br J Sports Med 35: 308-313.

2. Badel T, Jerolimov V, Panduric J (2007) Dental/Orofacial trauma in contact sports and intraoral mouthguard programmes. Kinesiology 39: 97-105

3. Tanaka N, Hayashi S, Amagasa T, Kohama G (1996) Maxillofacial fractures sustained during sports. J Oral Maxillofac Surg 54: 715-719.

4. Mourouzis C, Koumoura F (2005) Sports-related maxillofacial fractures: a retrospective study of 125 patients. Int J Oral Maxillofac Surg 34: 635-638.

5. Glendor $U$ (2009) Has the education of professional caregivers and lay people in dental trauma care failed? Dent Traumatol 25: 12-18.

6. Potter MR, Snyder AJ, Smith GA (2011) Boxing injuries presenting to U.S. emergency departments, 1990-2008. Am J Prev Med 40: 462-467.

7. Emerich K Nadolska-Gazda E (2013) Dental trauma, prevention and knowledge concerning dental first-aid among Polish amateur boxers. J Sci Med Sport 16: 297-301

8. Kumamoto DP, Maeda Y (2004) A literature review of sports-related orofacia trauma. Gen Dent 52: 270-280. 
Citation: Ozcan E, Dergin G (2013) Temporomandibular Joint Disorders and Preventive Methods in Boxing Athletes. J Sports Med Doping Stud 4: 134. doi:10.4172/2161-0673.1000134

Page 4 of 4

9. Jerolimov V (2010) Temporomandibular injuries and disorders in sport. Medical Sciences 34: 149-165

10. Jerolimov V, Seifert D, Carek V (2000) Injuries to the orofacial structure in a selected sample of handball players. Kinesiology 32: 93-98.

11. Lombardi S, Sheller B, Williams BJ (1998) Diagnosis and treatment of dental trauma in a children's hospital. Pediatr Dent 20: 112-120.

12. Flanders RA, Bhat M (1995) The incidence of orofacial injuries in sports: a pilot study in Illinois. J Am Dent Assoc 126: 491-496.

13. Du Brul EL (1980) Sicher's oral anatomy. ( $7^{\text {th }}$ edn.), C.V. Mosby, St. Louis (MO), 146-61, 174-209.

14. Sailors ME (1996) Evaluation of sports-related temporomandibular dysfunctions. J Athl Train 31: 346-350.

15. Okeson JP (1989) Management of temporomandibular disorders and occlusions. (2nd Edn.), CV Mosby St. Louis (MO) 3-26.

16. Gawlak D, Mierzwińska-Nastalska E, Mańka-Malara K, Kamiński T (2013) Comparison of usability properties of custom-made and standard self-adapted mouthguards. Dent Traumatol .

17. Federation Dentaire Internationale (1990) Guidelines for dental protection during sporting activities; Drugs and Sports, London.

18. Bechor R, Zadik Y (2008) An unusual lateral luxation of an upper incisor owing to long-term boxing without protection. Dent Traumatol 24: 550-552.

19. Ranalli DN (2000) Advances in sports dentistry. Dent Clin North Amer 44: 1-235.

20. Yildirim D, Dergin G, Tamam C, Moroglu S, Gurses B (2011) Indirect measurement of the temporomandibular joint disc elasticity with magnetic resonance imaging. Dentomaxillofac Radiol 40: 422-428.

21. Tippett SR (1990) Coaches guide to sport rehabilitation. Leisure Press, Champaign (Illinois).

22. Torg JS (1991) Athletic injuries to the head, neck, and face. $\left(2^{\text {nd }} e d n\right)$, Lea \& Febiger, USA.

23. Mellion MB, Michael WW, Shelton GL (2002) The Team physician's handbook. ( $3^{\text {rd }}$ edn), Hanley \& Belfus, USA

24. Fonseca (2000) Temporomandibular joint disorders, oral and maxillofacia surgery. WB Saunders Company, Philadelphia, Pennsylvania, USA

25. Mafee MF, Valvassori GE, Becker M (2005) Imaging of the Head and Neck. (2nd Edn.) Thieme Medical Publishers, Stuttgart, Germany.

26. Dergin G, Kilic C, Gozneli R, Yildirim D, Garip H, et al (2012) Evaluating the correlation between the lateral pterygoid muscle attachment type and internal derangement of the temporomandibular joint with an emphasis on MR imaging findings. Journal of Cranio-Maxillo-Facial Surgery 40: 459-463.

27. Jerolimov $\vee(2009)$ Temporomandibular disorders and orofacial pain. Medical
Sciences 33: 53-77.

28. World Dental Federation (FDI) Guidelines for dental protection during sporting activities. London.

29. Takeda T, Ishigami K, Hoshina S, Ogawa T, Handa J, et al. (2005) Can mouthguards prevent mandibular bone fractures and concussions? A laboratory study with an artificial skull model. Dent Traumatol 21: 134-140.

30. Lieger O, von Arx T (2006) Orofacial/cerebral injuries and the use of mouthguards by professional athletes in Switzerland. Dent Traumatol 22: 1-6.

31. Ranalli DN (2002) Sports dentistry and dental traumatology. Dent Traumato 18: $231-236$

32. Walilko T, Bir C, Godwin W, King A (2004) Relationship between temporomandibular joint dynamics and mouthguards: feasibility of a test method. Dent Traumatol 20: 255-260.

33. Labella CR, Smith BW, Sigurdsson A (2002) Effect of mouthguards on denta injuries and concussions in college basketball. Med Sci Sports Exerc 34: 41-44.

34. Winters JE Sr (2001) Commentary: Role of Properly Fitted Mouthguards in Prevention of Sport-Related Concussion. J Athl Train 36: 339-341.

35. Seals RR Jr, Dorrough BC (1984) Custom mouth protectors: a review of their applications. J Prosthet Dent 51: 238-242.

36. Patrick DG, van Noort R, Found MS (2005) Scale of protection and the various types of sports mouthguard. Br J Sports Med 39: 278-281.

37. Chalmers DJ (1998) Mouthguards. Protection for the mouth in rugby union Sports Med 25: 339-349.

38. Takeda T, Ishigami K, Ogawa T, Nakajima K, Shibusawa M, et al. (2004) Are all mouthguards the same and safe to use? The influence of occlusal supporting mouthguards in decreasing bone distortion and fractures. Dent Traumatol 20 : 150-156.

39. Shimoyama T, Masuda I, Numa T, Horie N (2009) Mandibular fracture with a mouth formed mouthguard in kickboxing. Dent Traumatol 25: 242-244.

40. Knapik JJ, Marshall SW, Lee RB, Darakjy SS, Jones SB, et al. (2007) Mouthguards in sport activities : history, physical properties and injury prevention effectiveness. Sports Med 37: 117-144.

41. Westerman B, Stringfellow PM, Eccleston JA, Harbrow DJ (2002) Effect of ethylene vinyl acetate (EVA) closed cell foam on transmitted forces in mouthguard material. Br J Sports Med 36: 205-208.

42. Tran D, Cooke MS, Newsome PR (2001) Laboratory evaluation of mouthguard material. Dent Traumatol 17: 260-265.

43. Craig M, Bir C, Viano D, Tashman S (2008) Biomechanical response of the human mandible to impacts of the chin. J Biomech 41: 2972-2980.

44. Walilko TJ, Viano DC, Bir CA (2005) Biomechanics of the head for Olympic boxer punches to the face. Br J Sports Med 39: 710-719. 